\section{BDA Annual General Meeting notice}

Notice is hereby given that an Annual General Meeting of members of the British Dental Association will be held in Glasgow at the Lomond Auditorium, SECC, at 10.00 am on Thursday 19 May 2005 to transact the following business:

Ordinary business

1. To receive and consider the audited accounts for the financial year ended 30 September 2004 and the report of the directors and of the auditors (to be published as a supplement to the $B D J$ )

2. To appoint BDO Stoy Hayward LLP as auditors and to authorise the Executive Board to fix their remuneration

3. To consider and, if thought fit, to pass the following resolutions recommended to the meeting by the Executive Board:

a) That Sue Greening be elected President for 2006-07

b) That the 2006 Annual General Meeting be held in Birmingham

4. To consider any other recommendations of the Executive Board.

Dated this day, the 23rd of April 2005, by order of the Executive Board.

I.M. Wylie

Chief Executive

Solving the UK's dental crisis a maniesto from the British Dental Association

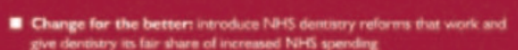

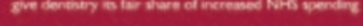

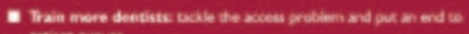
pasens queces

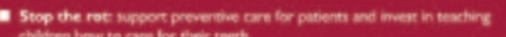

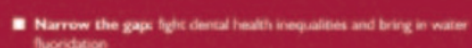

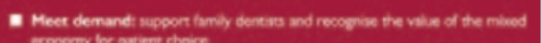

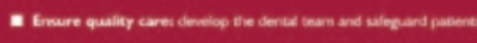
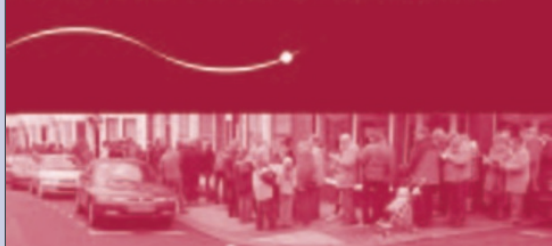

New dental research award

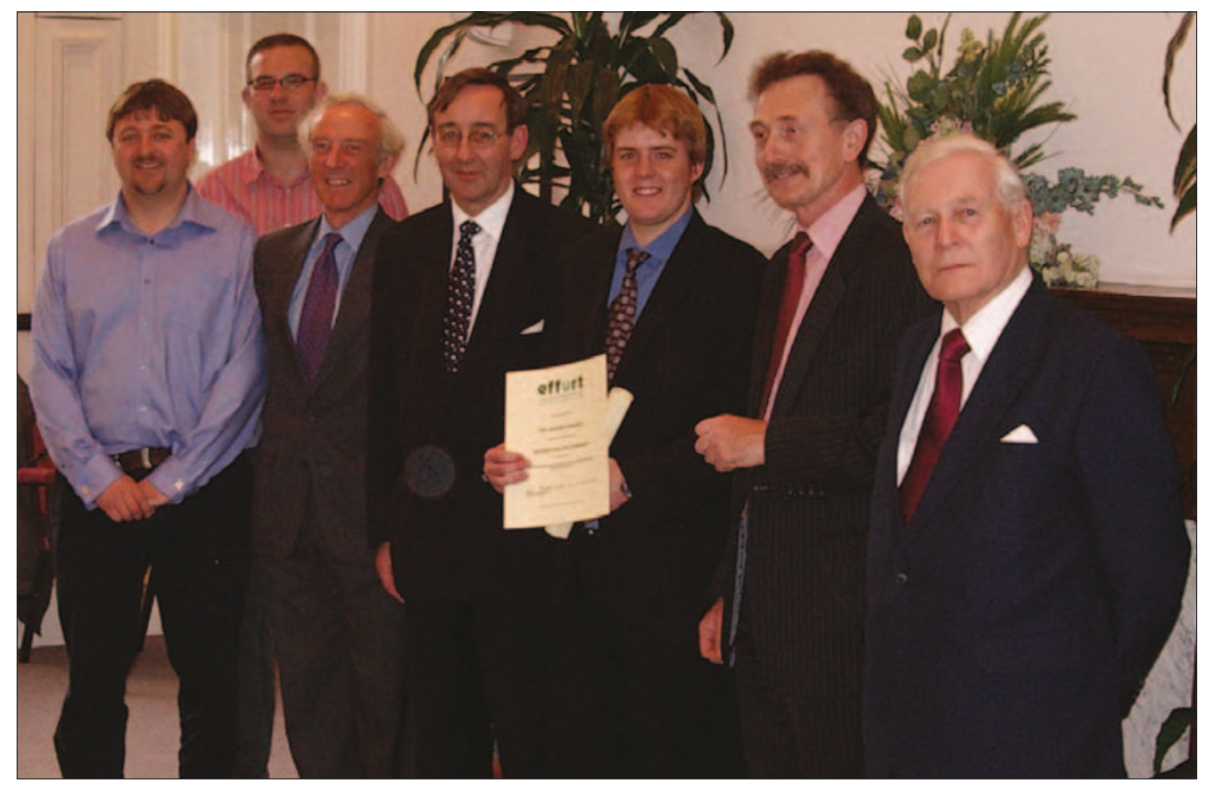

Dr Jeffrey Round has been awarded the first Eastman Foundation for Oral Research and Training (EFFORT) PhD Fellowship. The Fellowship is worth $£ 60,000$ over three years and will support his study entitled $A$ Comprehensive Evaluation of Periodontal Therapy (The CEPT Study). The research aims to investigate outcomes of periodontal treatment using quantitative methods. It is hoped this approach will provide data that is relevant for decision-making by both patients and clinicians and will address a critical research gap in dentistry. The Foundation is a registered charity whose aims include promoting the prevention and study of diseases of the oral and dental tissues, allied structures and allied subjects and improving the standard of knowledge of the means of prevention, diagnosis, treatment and cure of such diseases. Pictured above from left to right are Dr David Spratt, Dr Mark Lewis, Professor Andrew Rugg-Gunn, Professor Crispian Scully CBE, Dr Jeffrey Round, Professor Ken Eaton and Professor Tony Naylor.

\title{
BDA launches manifesto
}

The British Dental Association has launched its manifesto for UK dentistry. It is urging prospective parliamentary candidates to make dentistry a priority during the general election campaign.

The Association reiterates its call for greater investment in dental services as access remains a problem in most areas of the UK and it also wants to see access problems tackled with a significant increase in training places for would-be dentists.

There are six key points of the BDA's manifesto which include introducing NHS dentistry reforms that work, give dentistry its fair share of increased NHS spending, train more dentists, tackle access problems, support preventive care for patients and support family dentists.
It also wants Governement to recognise the value of the mixed economy for patient choice, develop the dental team and safeguard patients.

The manifesto lends its support to the campaign to make school vending machines include healthier options and calls for water coolers, rather than fizzy drinks, to be made more readily available in schools.

It repeats the BDA's support for targeted water fluoridation schemes as a way of significantly reducing dental health inequalities.

There are four manifestos - one each for England, Scotland, Wales (including a Welsh language version) and Northern Ireland. For more information visit www.bda.org 


\section{Promoting smoking cessation}

Military dental professionals from Dental Centre Fallingbostel took the opportunity to promote smoking cessation with gusto on National No Smoking Day.

They staged exhibitions and displays and provided leaflets and other literature to military personnel and their families. Smokers were offered carbon monoxide readings and results showed that the highest reading was 32 and the lowest was 4 .

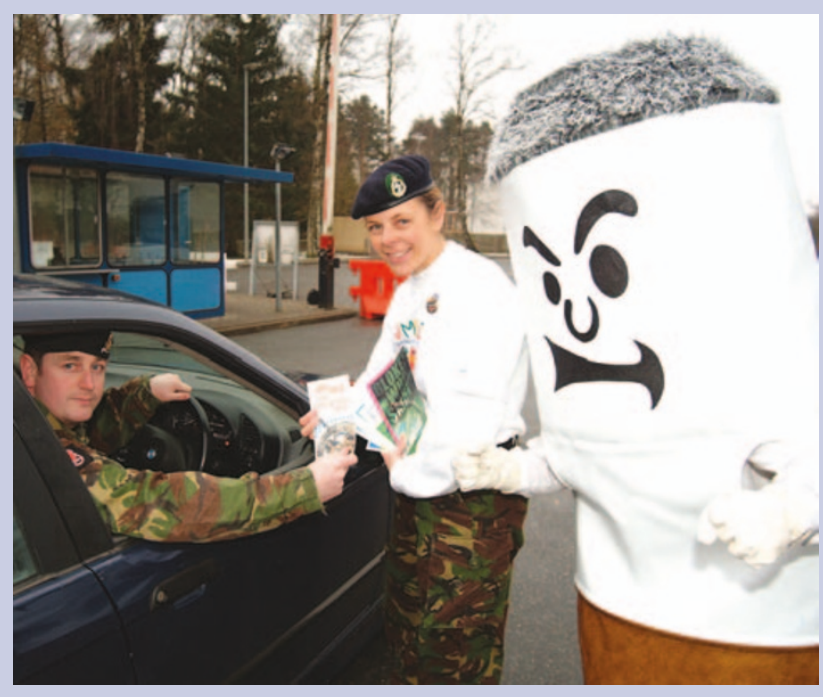

\section{New career pathway for academics launched}

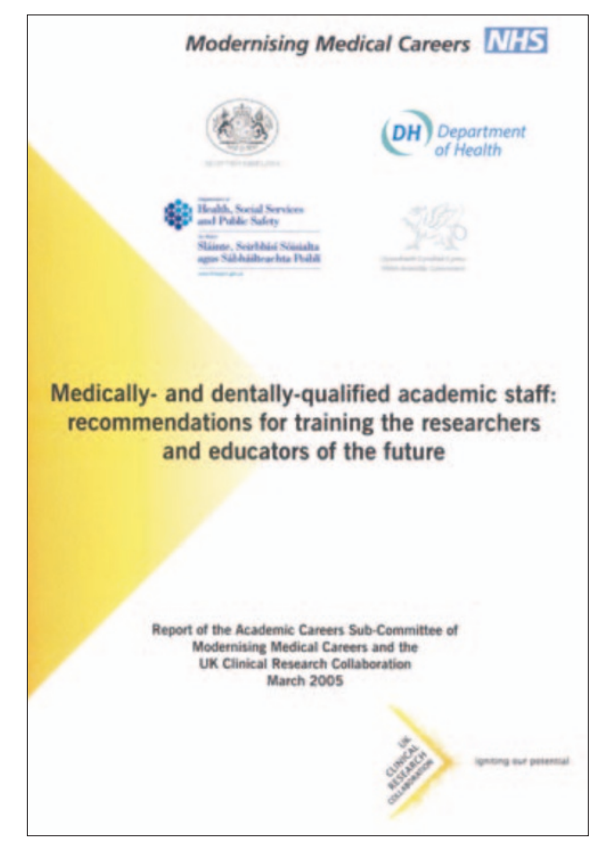

A new report has been launched that sets out a clear training pathway for doctors and dentists who wish to follow a career in academic medicine and dentistry. The report, Recommendations for Training the Researchers and Educators of the Future, was produced by the UK Clinical Research Collaboration (UKCRC) and the Department of Health's Modernising Medical Careers (MMC) initiative.

The report outlines that figures for academic clinicians have decreased rapidly in recent years, and warns that this could have dire consequences for the future of scientific innovations in these fields in the UK. It aims to remove the roadblocks which can deter individuals from taking up a career in academic medicine or dentistry.

The Government is committing £2.5 mil- lion in 2005/6 in an attempt to reverse the decline in numbers and to begin the process of establishing a new integrated academic training programme, which will provide the foundation for academic clinicians.

Dr Mark Walport, chair of the Academic Careers Sub-Committee of UKCRC and MMC, warned of the perilous state of academic medicine and dentistry in the UK today: "Without the continual development of experienced research clinicians the training of future doctors and dentists is in jeopardy. Innovation will grind to a halt and patients will suffer as a result. The nation desperately needs top quality academic clinicians in all disciplines to provide professional leadership and innovation, but currently young doctors and dentists do not perceive an academic career as attractive."

Three main reasons have been identified as to why young medics are unenthusiastic about a career in academic medicine, which are a lack of a clear route of entry and a transparent career structure, lack of flexibility in the balance of clinical and academic training and in geographical mobility; and a shortage of properly structured and supported posts upon completion of training.

Its recommendations on how to remove barriers and encourage research at all stages of clinical training include measures to encourage medical and dental students to take up and develop a research career at School stage. It also proposes the encouragement of a new generation of clinical academics, partly through the creation of a cohort of 'new blood' senior lectureship posts and also through the removal of financial disincentives to undertake research. 


\section{Group meeting}

The Dental Academic Staff Group (formerly UDT \& RW Group) will be holding their next AGM on 11 May 2005, 11:00am, BDA Headquarters, 64 Wimpole
Street, London. Group members wishing to attend should contact Marlene Lough at the BDA on 0207563 4141, or by email at m.lough@bda.org, for further details.

\section{GDC by-election announced}

The GDC is holding a by-election for the England, Isle of Man, and Channel Islands constituency to fill the vacancy left by David Barnard who resigned from the Council at the end of last year for personal reasons.

The Notice of Election was published in The Times and on the GDC website on Wednesday 2 March 2005. Also, the President wrote to all dentists with a

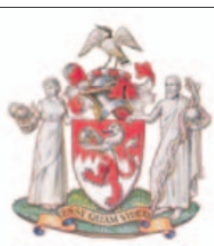

\section{General Dental Council}

registered address in England, the Isle of Man and the Channel Islands to encourage them to take part in the election as candidates and/or voters. The nomination period for candidates ran from 2 March to 31 March 2005 and the result of the by-election will be announced on 26 May 2005.

\section{Action plan tackles discrimination}

NHS Employers has recently launched an action plan to tackle discrimination and harassment affecting doctors and dentists. Fourteen organisations have signed up to the action plan, known as Equal Values, Equal Outcomes. These include the Department of Health, the General Medical Council, the British Dental Association and the General Dental Council. Action points include improving access to medical and dental education, opening up career opportunities, and developing disciplinary procedures that are open and equitable.

NHS Employers is the employers' organisation for the NHS in England, and its work programme includes pay negotiations, health and safety, diversity, recruitment and retention, the NHS Pension Scheme review and whistleblowing. It claims that only $12 \%$ of students accepted into medical schools come from households headed by unskilled, partly skilled and skilled manual workers, even though these households make up 40\% of the population and that only $22 \%$ of consultants come from black or minority ethnic backgrounds, yet well over a third of all doctors and dentists classify themselves in this way.

"People from a wide and diverse range of backgrounds should be given a chance to train as a doctor or dentist," says NHS
Employers head of equality and diversity Carol Baxter. "This action plan is about building on work already begun to ensure they are given that chance and that all dentists and doctors are given equal career opportunities regardless of their religious beliefs, whether they are male or female, come from a minority ethnic background, are disabled or are gay, lesbian or bi-sexual."

Ms Baxter also added that although a high proportion of NHS doctors and dentists come from black and minority ethnic backgrounds, many do not reach the highest positions and there are persistent concerns that disciplinary mechanisms discriminate against them. She commented: "Students whose parents come from lower socio-economic groups are less likely to go to medical or dental school. More than half of dental and medical students are now women but access to flexible working for both male and female doctors and dentists still needs to be greatly improved."

NHS Employers will be setting up a small group of equality and diversity experts to objectively review progress against the action plan in a year's time.

Equal Values, Equal Outcomes is available on the NHS Employers website at www.nhsemployers.org.

\section{Death notice}

Dr John Brackenridge, former past President of the BDA's Middlesex \& Herts
Branch and life member, sadly died on 5 April. He is survived by his wife, Joan. An obituary will be published in due course. 